\title{
Cardiac Conduction Disorder
}

National Cancer Institute

\section{Source}

National Cancer Institute. Cardiac Conduction Disorder. NCI Thesaurus. Code C78245.

A disorder affecting the conduction system that sends electrical signals in the myocardium. 